\title{
O BIM APLICADO NO PLANEJAMENTO EM OBRA DE HABITAÇÃO DE INTERESSE SOCIAL: ESTUDO DE CASO
}

\author{
Felipe Madruga ${ }^{(1)}$, Sandra Ribeiro ${ }^{(1)}$ \\ (1) Centro Universitário do Rio Grande do Norte, Natal
}

\begin{abstract}
Resumo
O déficit habitacional é um problema crônico no Brasil e atinge, especialmente, as famílias de baixa renda. Em meio a isso, grande parte da literatura relata a importância do uso de novos métodos de trabalho e tecnologias na construção civil para fomento de moradia. O vigente artigo descreve a aplicação do BIM na elaboração do Planejamento de uma habitação de interesse social, através das ferramentas: TQS ${ }^{\circ}$, Revit ${ }^{\circledR}$, Navisworks ${ }^{\circledR}$ e MS Project. A metodologia adotada foi o estudo de caso e os resultados constataram a interoperabilidade entre os softwares utilizados, a facilidade de extração de quantitativos a partir dos modelos virtuais, bem como a comunicação desses modelos com o planejamento, possibilitando a visualização da programação da obra. Além de poder prever interferências ainda na etapa de projeto, diluindo atrasos e conservando o caminho crítico. A pesquisa contribui na difusão e no entendimento do BIM, bem como fomentar um caminho para mitigar um problema social.
\end{abstract}

\section{Introdução}

A indústria da construção civil no Brasil ainda é vista como ultrapassada e requer a implementação de metodologias, técnicas e tecnologias que visam a mitigação de desperdícios e a maior produtividade e qualidade na execução de obras. Essa ação é essencial para o fomento de moradia e até mesmo para a inserção desse setor na era da indústria 4.0. Nesse cenário, o Building Information Modeling (BIM) emerge como um caminho promissor, especialmente, por apresentar novos processos e ferramentas que possibilitam vários ganhos como a extração automática de quantitativos e a construção e visualização do planejamento. Ressalta-se que recentemente foi publicado o decreto $\mathrm{N}^{\circ} 10.306,02$ de abril de 2020, o qual visa a difusão e a utilização dessa metodologia em obras públicas a partir de 2021.

O BIM, visto ainda como revolucionário, pode ser definido como meio que possibilita um ambiente que integra todo o ciclo de vida da edificação a partir da construção virtual de modelos digitais precisos e baseados em objetos paramétricos [1;2]. Estes modelos, além de possibilitar o protótipo do edifício em meio digital, compõe um banco de dados que atua desde as fases iniciais do projeto, passando pela simulação da construção e chegando à operação do edifício [3]. 
Uma parte da literatura descreve o BIM a partir de dimensões (do 3D até 9D) que representam algumas das etapas do ciclo de vida do edifício. A quarta dimensão refere-se ao uso do modelo aplicado ao planejamento, ou seja, o modelo BIM é visto a partir da perspectiva do tempo. Paralela a confecção do empreendimento as ferramentas dessa metodologia são capazes de quantificar a parcela temporal de cada elemento, tornando possível a visualização da obra em diferentes momentos da construção, além de identificar interferências e alternativas para as mais diversas situações.

Em termos gerais, a visualização e a simulação das sequências dos processos construtivos facilitam a tomada de decisão nas etapas de planejamento e construção [4] e possibilitam o controle visual do andamento do canteiro da obra. Apesar das vantagens supracitadas do 4D, algumas pesquisas $[5 ; 6 ; 7 ; 8]$ apontam a necessidade de mais estudos que explorem, especialmente, o fluxo de trabalho, os processos e as ferramentas utilizadas nessa dimensão.

Por outro lado, o déficit habitacional é um problema crônico no Brasil, apesar dos esforços vistos nos programas habitacionais que foram implementados pelo Estado nas últimas décadas. $\mathrm{Na}$ verdade, essas ações refletem, muitas vezes, soluções pautadas na padronização e produção em massa, gerando economia de escala. E construções executados a partir de métodos tradicionais, com baixo orçamentos e produtos de má qualidade, além de outros transtornos. $\mathrm{O}$ emprego do BIM nessa tipologia se justifica para criar um caminho mais assertivo e mitigar parte desses problemas. Diante do exposto, o presente trabalho visa descrever a aplicação da metodologia BIM no planejamento de uma habitação de interesse social a partir de um estudo de caso.

\section{Metodologia}

O presente trabalho tem como estratégia a adoção de um estudo de caso que simulará o planejamento em 4D de uma habitação de interesse social. Para tanto, se fez necessário no primeiro momento um estudo do projeto e modelo arquitetônico e hidráulico executado em um trabalho de conclusão de curso [8]. Em seguida, foi realizado o desenvolvimento dos modelos BIM que não foram contemplados no trabalho supracitado, sendo eles o projeto elétrico, sanitário e estrutural. Para tal consumação foram utilizadas as ferramentas digitais TQS (para o projeto de estrutura) e Autodesk Revit (para os projetos de instalações).

No segundo momento, os projetos/modelos foram reunidos em um único arquivo, denominado modelo federado, passando por um breve estudo de compatibilização a fim de identificar e posteriormente eliminar as interferências entre as disciplinas de arquitetura, instalações e estrutura. Nessa fase foi adotada a ferramenta Autodesk Navisworks. Na sequência fez-se o levantamento dos quantitativos e os resultados foram inseridos em uma planilha do Excel.

No terceiro momento, com os dados obtidos do modelo federado, deu-se início ao planejamento da obra com auxílio da ferramenta MsProject. Foram introduzidos os dados extraídos (insumos) mais o fator de tempo. Com a programação montada realizou-se uma simulação do tempo no software Autodesk Navisworks, cujo objetivo foi montar o cronograma-físico da obra, ou seja, obter a visualização dos parâmetros temporais de projeto.

Ao final, foi constatado os desafios para implementação dessa metodologia, após todas as etapas executadas, bem como as vantagens do BIM no planejamento de habitações de interesse social. 


\section{Elaboração dos modelos BIM}

\subsection{Análise do modelo base}

Vale lembrar que o empreendimento escolhido para o estudo é de pequeno porte e representa uma habitação de interesse social (Figura 1) com 51,69 $\mathrm{m}^{2}$ de área construída e conta com os seguintes ambientes: 02 quartos, sala, cozinha, banheiro, área de serviço e terraço. A residência escolhida para o estudo, embora apresente uma quantidade pequena de área construída, tem sua importância devido à alta replicabilidade no território brasileiro.

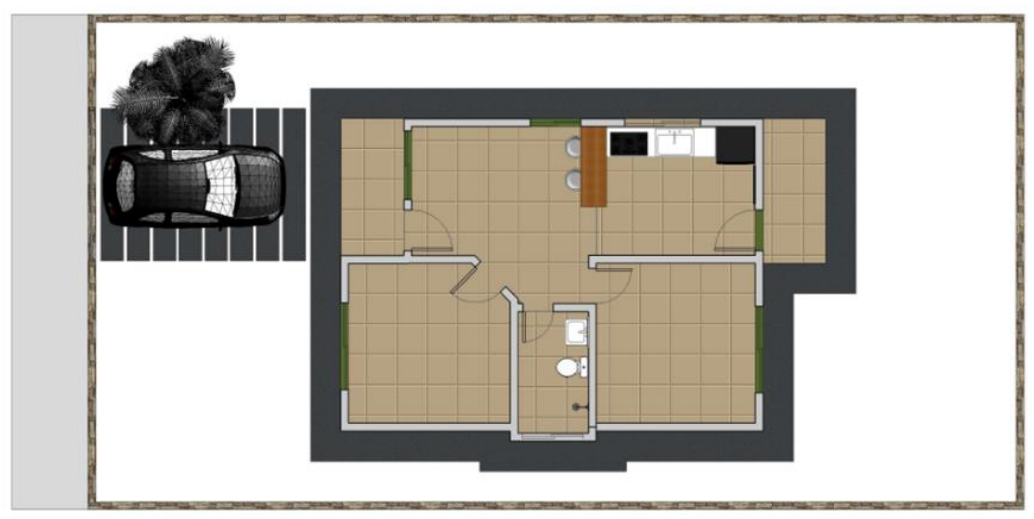

Figura 1: Planta baixa da Habitação de Interesse Social.

Além do projeto/modelo arquitetónico, conta-se com projeto hidráulico de água fria em 3D (Figura 2)

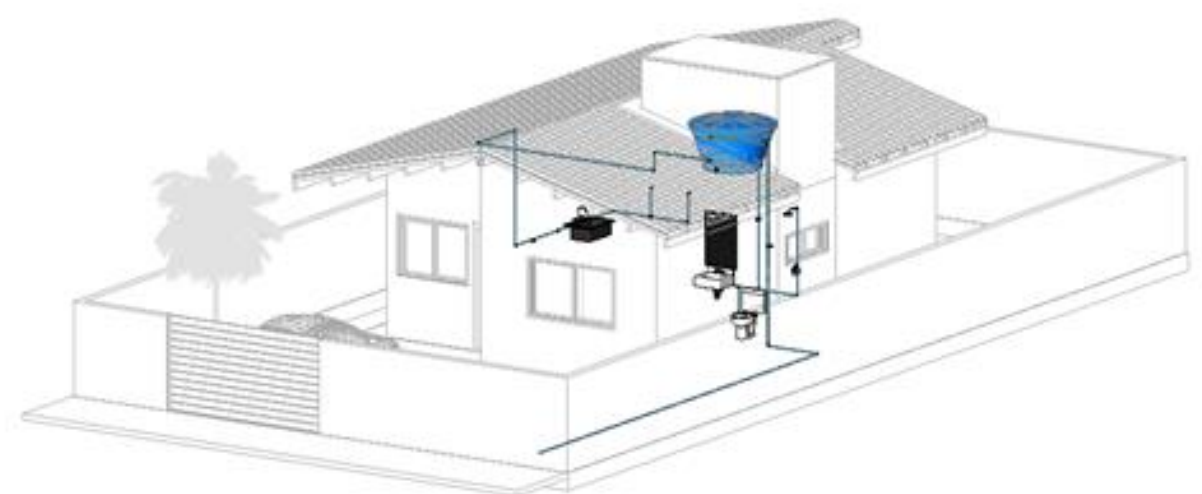

Figura 2: Modelo BIM do projeto hidráulico.

\subsection{Projetos de esgotamento sanitário}

No projeto de esgotamento sanitário, ainda foi necessária uma análise mais detalhada do terreno entorno da edificação, para a locação das caixas de inspeção e seu deslocamento até a fossa séptica e em seguida o sumidouro (Figura 3), que também passaram por um processo de organização volumétrica para encontrar o local mais adequado para implementação. Outro fator relevante para esse tipo de projeto é o retorno dos gases, desse modo foi inserida a tubulação de ventilação (representado pelo tubo laranja na Figura 3. Todo o projeto atendeu a NBR 8160. 


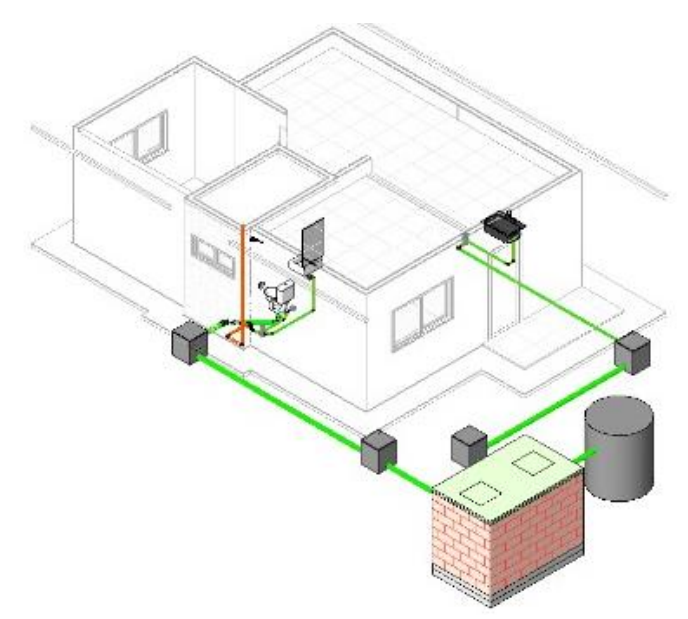

Figura 3: Modelo BIM do projeto de esgotamento sanitário.

\subsection{Projeto de instalação elétrica}

Foi feito um prévio estudo dos ambientes, pensando nas necessidades luminosas, na melhor distribuição de tomadas (TUGs e TUEs), nos acessos aos interruptores e ainda em uma locação sem danos para os outros componentes dos demais projetos (hidrossanitário e estrutural). Com todos os componentes devidamente instalados, os pontos de luz foram interligados formando os sistemas, que recebem separadamente uma fonte de energia dos disjuntos gerais presentes no quadro de distribuição. A locação do quadro foi um dos pontos de estudo, pensando na praticidade de utilização, como também na questão estética do ambiente, como apresentado na figura 4.

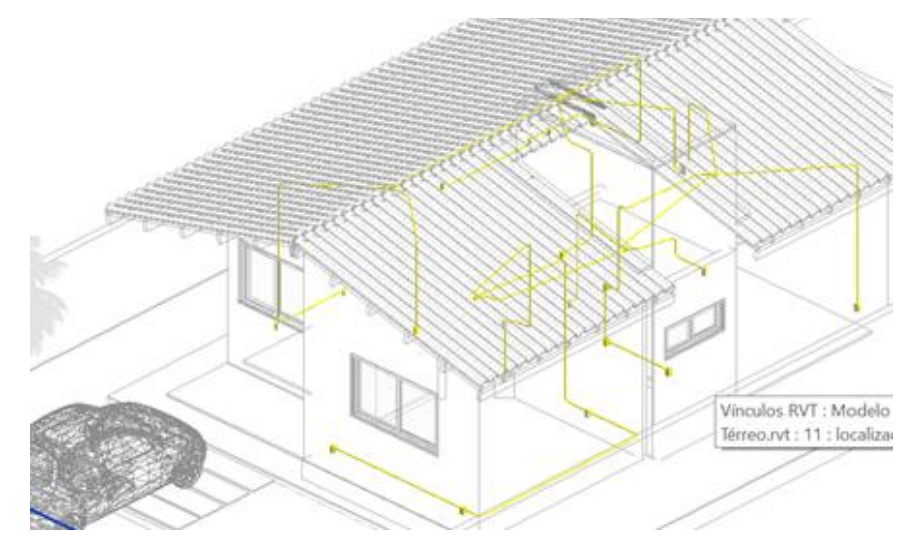

Figura 4: Modelo BIM do projeto elétrico.

\subsection{Projeto estrutural}

A concepção de um modelo estrutural é a que mais se difere. Trata-se de um estudo global da edificação, levando em consideração a resistência dos materiais utilizados, os elementos de contraventamento e travamento, a geometria das vigas e pilares, os vãos livres, os carregamentos e suas transmissões, as fundações, as armaduras e majorando de todos esses requisitos, além das exigências arquitetônicas. Inicialmente, foi feita a importação da planta baixa, no formato DWG, para dentro do software TQS. Com a planta inserida e posicionada, foi modelada os elementos estruturais: pilares vigas e fundações (Figura 5). 


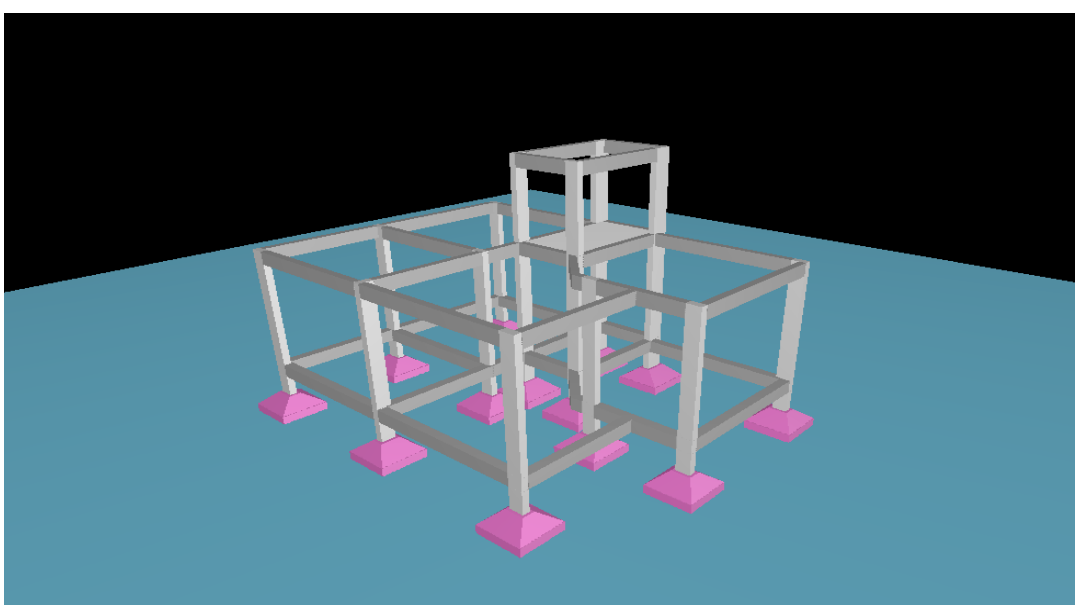

Figura 5: Modelo estrutural em 3D.

O processamento global foi feito, pedindo como resultado apenas os carregamentos pontuais de cada pilar, para efetuar o cálculo das fundações partindo das tensões solicitantes fornecidas. Devido à falta de aprofundamento como por exemplo uma local preciso de aplicação e um estudo de sondagem real, foram feitas aproximações baseadas no padrão do solo potiguar. Assim a escolha de sapatas isoladas, assentadas a 1,30m de profundidade, foi feita para promover a transmissão dos carregamentos para o solo.

\section{Compatibilização}

A criação de um modelo federado é a base para utilização de qualquer software com objetivo de compatibilizar. Como todos os projetos/modelos já foram executados e unidos, o papel do analista passa a ser o de criar grupos de elementos que partilhem do mesmo nicho na obra, e com uma visão mais a fundo, esses agrupamentos são feitos pensando nas atividades que serão criadas para futuramente associá-los ao planejamento 4D do empreendimento.

Esse agrupamento de elementos é chamado de "Sets" e é considerado por muitos a alma da compatibilização, especialmente no programa Navisworks. Um arranjo bem executado da distribuição dos sets gera testes de compatibilização muito mais eficientes e com uma maior possibilidade de aprofundamento em detalhes.

A partir da conclusão dos sets, foi dado início ao processo de compatibilização. Por meio da ferramenta "Clash Detective" os elementos são então selecionados para que a plataforma identifique interferências de acordo com as exigências (hard ou soft clash) e as tolerâncias, entre dois ou mais sets, exemplo: tubulações hidráulicas, eletrodutos e vigas (Figura 6). 


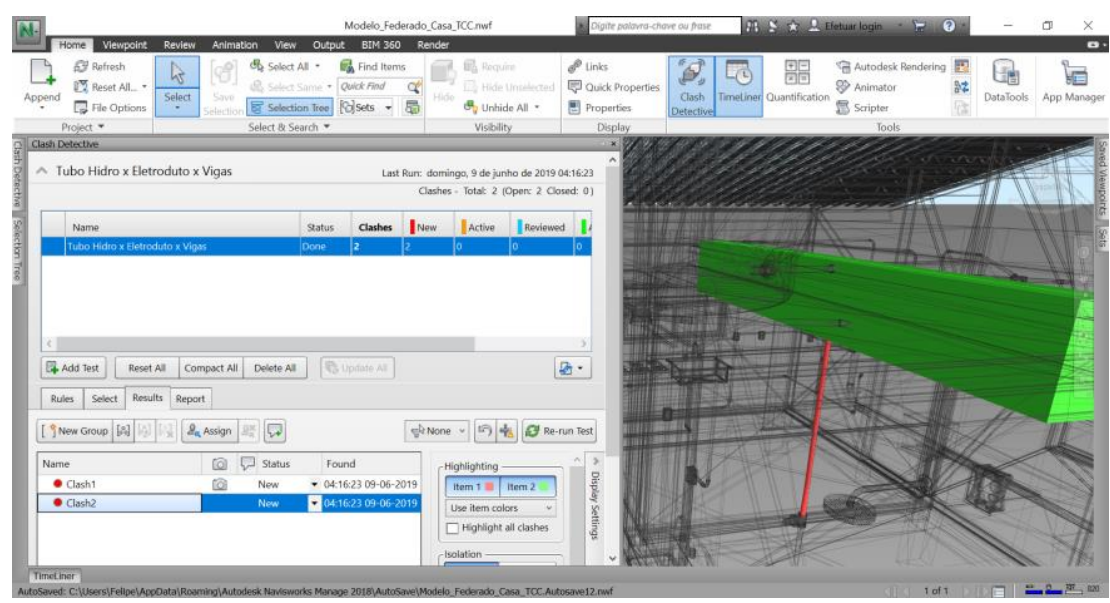

Figura 6: Clash Detective.

Dentro de um projeto bem executado, todos os grupos de elementos devem ser testados a fim de minimizar as incompatibilidades e levar para obra o projeto livre de interferências.

\section{Planejamento}

O momento final desse estudo de caso resultou na criação de um planejamento de obra, projetado para garantir uma execução rápida e eficiente, focando inicialmente na sequência das tarefas, em seus tempos de duração e nos encarregados. Posteriormente, foi feita uma verificação detalhada abordando o tempo de folga das atividades e o caminho crítico. As tarefas estabelecidas exigem uma certa quantidade de funcionários (recursos) trabalhando a um ritmo médio estimado (taxa de produtividade), que fornece um tempo de desenvolvimento mais próximo do real e de fundamental importância para estimar numericamente quantos trabalhadores serão necessários por atividade desempenhada. Por se tratar de uma sequência repetitiva de análises, foi desenvolvida uma planilha, em formato de Excel (Figura 7).

\begin{tabular}{|c|c|c|c|c|c|c|c|c|c|c|c|c|c|c|c|c|c|c|c|c|c|c|c|}
\hline \multicolumn{24}{|c|}{ QUADRO DE DURAÇÃO DAS ATIVIDADES E RECURSOS } \\
\hline \multirow[b]{2}{*}{ ATIVIDADE } & \multirow[b]{2}{*}{ UNID. } & \multirow[b]{2}{*}{ QTDE } & \multicolumn{8}{|c|}{ EQUIPE BÁSICA } & \multirow{2}{*}{\multicolumn{2}{|c|}{ 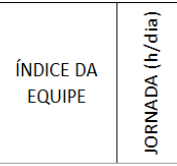 }} & \multirow[b]{2}{*}{$\begin{array}{l}\text { DIAS DA } \\
\text { EQUIPE } \\
\text { BÁSICA }\end{array}$} & \multirow[b]{2}{*}{$\begin{array}{c}\text { DURAÇÃO } \\
\text { ADOTADA } \\
\text { (dias) }\end{array}$} & \multirow[b]{2}{*}{$\begin{array}{c}\text { QTDE } \\
\text { DE } \\
\text { EQUIPES }\end{array}$} & \multicolumn{8}{|c|}{ RECURSOS } \\
\hline & & & 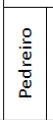 & 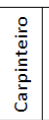 & $\begin{array}{l}\frac{\overline{0}}{0} \\
\frac{0}{\pi} \\
\frac{\pi}{4}\end{array}$ & 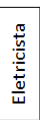 & 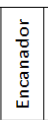 & 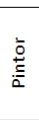 & 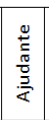 & 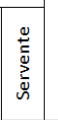 & & & & & & 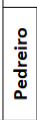 & 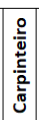 & 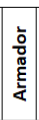 & 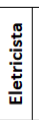 & 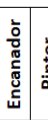 & & 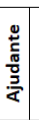 & 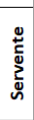 \\
\hline \multicolumn{24}{|l|}{ Piso - Térreo } \\
\hline Instalações hidráulicas - Térreo & un & 1,00 & 1,00 & & & & 1,00 & & 0,50 & 1,02 & \begin{tabular}{|l|l|}
8 & h/un \\
\end{tabular} & 8 & 1 & 1 & 1 & 1 & & & & 1 & & 1 & 1 \\
\hline Instalação elétrica - Térreo & un & 1,00 & & & & 1,00 & & & 1,00 & & \begin{tabular}{|l|l|}
24 & $\mathrm{~h} / \mathrm{un}$ \\
\end{tabular} & 8 & 3 & 3 & 1 & & & & 1 & & & 1 & \\
\hline Execução de formas - Térreo & $\mathrm{m}^{2}$ & 6,78 & & 1,00 & & & & & 0,50 & & \begin{tabular}{ll|}
1,83 & $\mathrm{~h} / \mathrm{m}^{2}$ \\
\end{tabular} & 8 & 2 & 2 & 1 & & 1 & & & & & 1 & \\
\hline Concretagem - Piso térreo & $\mathrm{m}^{3}$ & 7,57 & $|1,00|$ & & & & & & & $\mid 1,33$ & \begin{tabular}{l|l|}
1,5 & $\mathrm{~h} / \mathrm{m}^{3}$ \\
\end{tabular} & 8 & 2 & 2 & 1 & 1 & & & & & & & 1 \\
\hline
\end{tabular}

Figura 7: Planilha do quadro de duração das atividades e recursos.

Essa tabela tem como dados de entrada: os quantitativos da atividade, os integrantes que participarão, suas taxas, o índice da equipe e a jornada diária de trabalho (em horas por dia). E valores de saída mostrando o tempo de duração de cada tarefa, para aquela quantidade de equipes 


\subsection{Planejamento no MsProject}

Quanto mais detalhado e refinado é um planejamento, mais eficiente ele se torna. No entanto, as chances de erros e conflitos aumentam a medida em que este vai ganhando corpo. Para auxiliar o desenvolvimento o MsProject torna-se um aliado indispensável, partindo dos processos de criação até os mais simples, como visualização. Uma característica que define uma sequência, é a existência de uma ordem que será seguida, no planejamento, essa ordem é garantida pelas "predecessoras". Na plataforma de gestão da obra, elas representam uma coluna, onde ao inserir o número da linha correspondente, o gráfico de gantt automaticamente posiciona seu início no dia subsequente a conclusão da predecessora.

A plataforma possibilita a visualização (ainda em forma experimental) de atividades que começam simultaneamente (mesmo com durações diferentes) e de atividades que necessitam do término de uma predecessora para ter início. Nesse estudo, após todas as adequações o software permite checar uma "planilha de recursos" que ele mesmo já calcula automaticamente quantas pessoas de cada serão necessárias para que a obra flua sem que ajam conflitos de tempo, no qual um trabalhador tenha que desempenhar duas atividades em um mesmo período.

A ferramenta de planejamento escolhida tem uma função que intensifica o estudo visual das sequências de atividades e disponibilidade dos recursos. A introdução de uma latência nas tarefas, ou seja, uma tarefa que teria início com o fim de sua predecessora, pode ter uma latência de menos dois dias (-2d), assim ela começará a acontecer dois dias antes do término do antecedente.

$\mathrm{Na}$ figura 8 temos uma situação onde a latência seria aplicada da melhor forma, gerando alta produtividade e rendimento, reduzindo o tempo final da obra. Porém, como alerta o MsProject, por meio de um indicador na primeira coluna, as tarefas apresentam uma necessidade maior de recursos para conseguir executar o que está sendo imposto na quantidade de tempo fornecida.

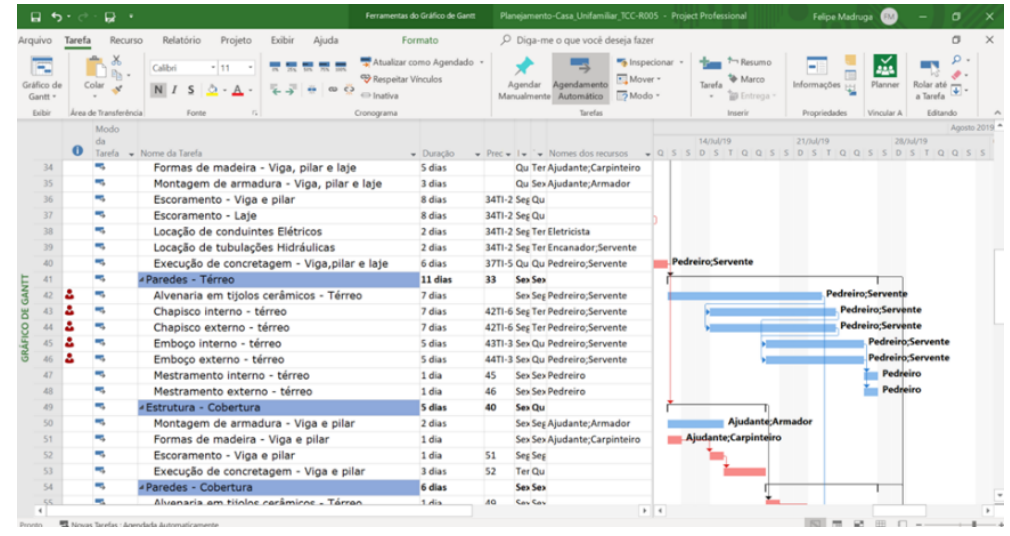

Figura 8: Teste de latência 1.

A limitação de apenas uma equipe por vez inviabiliza a execução da atividade da maneira mostrada, mesmo sendo a mais adequada, um planejamento é feito para encontrar seu melhor modo de produção com as variáveis que lhe são fornecidas. Para tal, o gestor responsável fica encarregado de estudar os caminhos críticos e as folgas da Estrutura Analítica do Projeto (EAP), até encontrar o caminho mais viável. Representado na Figura 9, é exibido outro método de execução que cria um caminho crítico (destacado pela cor vermelha) e reduz em um dia as folgas, e muito embora consiga viabilizar a execução, acarreta um acréscimo de cinco dias para conclusão da atividade. 


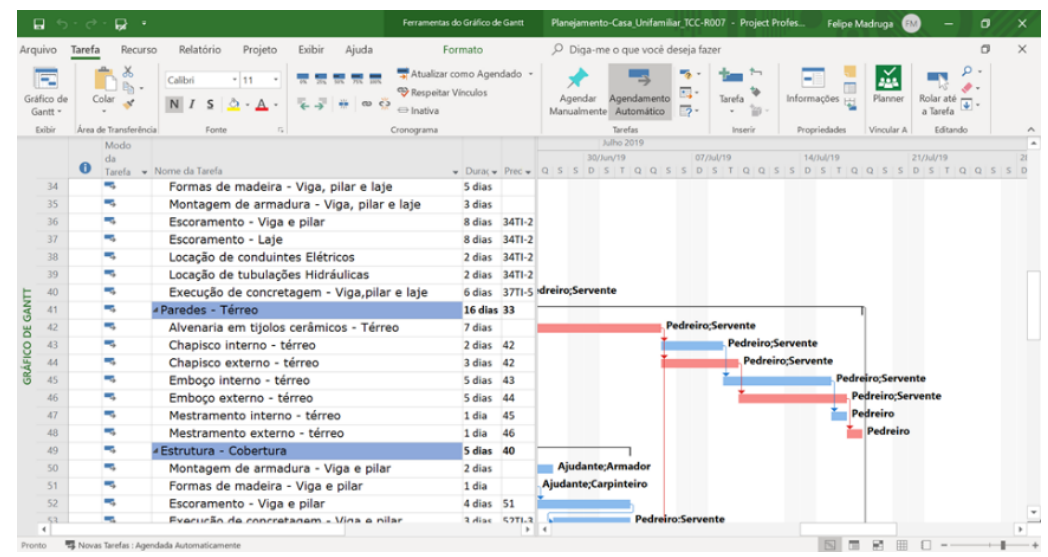

Figura 9: Teste de latência 2.

Com o fim de todo o estudo e variações executadas o planejamento enfim atinge um ideal momentâneo, compreendido como um cronograma que traçou o planejamento de uma residência de pequeno porte em um período de quatro meses e 13 dias, um intervalo totalmente aceitável e dentro dos padrões de uma construção desse estilo. Entretanto como supracitado, este é o "ideal momentâneo", pois um bom planejamento presa pela constante evolução e adequação, não apenas pré-obra, mas principalmente durante, para promover seu acompanhamento e adequar o planejamento em caso de atrasos ou antecipações. Buscando uma melhor forma de promover esse controle no decorrer da produção do empreendimento, a melhor alternativa encontra-se em atrelar o planejamento a uma plataforma com suporte para quarta dimensão do Building Information Modeling.

\subsection{Planejamento 4D-BIM}

De volta ao Navisworks, o planejamento da obra vai ser enfim concluído, mas de modo mais detalhado que facilite a checagem visual de produção. Após a adequação do modelo federado, o software é capaz de vincular cada "set" criado, a uma "task" em seu "TimeLiner". As tasks por sua vez, seriam as atividades da EAP criada no item anterior, e o TimeLiner é a ferramenta capaz de criar uma sequência construtiva a partir de suas datas de início e término, conseguindo criar um diagrama de gantt, similar ao do MsProject, mas com menos requintes e recursos.

A importação da EAP na ferramenta da Microsoft é feita de forma totalmente automática, mesmo de fornecedores diferentes as plataformas têm suporte para se comunicarem. Logo a estrutura analítica criada pode ser inteiramente aproveitada na linha de tempo do Navisworks, já sendo inserida com suas datas de início e fim de cada atividade. Verificando-se na prática a interoperabilidade desses programas.

A EAP depois de finalizada entra no fator diferencial do software da Autodesk, que é a simulação do empreendimento de acordo com sua linha temporal criada. Esse recurso permite ter o controle do acompanhamento físico da obra assim que ela é executada, onde é possível escolher qualquer dia no intervalo de tempo do planejamento e ser capaz de enxergar como está o protótipo e como deve estar à execução, com todo o aspecto visual e as porcentagens de execução de cada atividade (Figura 10). 


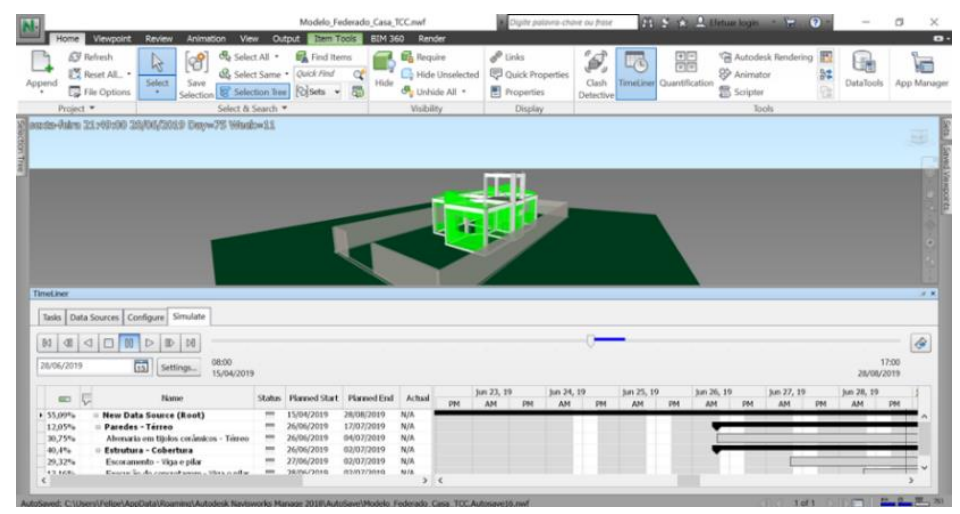

Figura 10: Simulação da EAP.

\section{Conclusão}

Este estudo defende a vantagem da utilização do BIM perante os métodos tradicionais de produção, em todos os aspectos relevantes, sejam eles de manuseio de plataforma, compatibilização, correção, análises e afins. Pode-se concluir que os softwares BIM, proporcionaram uma maior fluidez, agilidade e confiabilidade, garantindo a metodologia um destaque e uma consolidação como uma ferramenta de auxílio quase que necessária para as práticas da arquitetura, engenharia e Construção civil. Vale destacar alcances pontuais com a conclusão do referido trabalho:

- Modelo federado totalmente compatibilizado por meio de arquivos IFC.

- Considerável parcela de tempo, dedicada a implementação da metodologia.

- Alto nível de interoperabilidade, mesmo entre ferramentas de diferentes fornecedores.

- Planejamento com duração de 4 meses e 13 dias.

O tempo de adaptação da metodologia BIM, sem dúvidas, é o maior empecilho para sua implementação. O crescimento do mercado e o aumento do número de softwares provocaram um conflito quando se busca uma linearidade nas informações, porém com o conhecimento, esse conflito se dissipa e possibilita o uso pleno e da forma mais produtiva de cada ferramenta. Apesar dos danos causados pela implementação e dos obstáculos mostrados no estudo, eles de forma alguma inviabilizam a adoção da metodologia, muito pelo contrário, após o término do trabalho é possível afirmar que o BIM é hoje indispensável para melhoria da qualidade dos projetos e uma metodologia que desmistifica o planejamento, viabilizando sua adoção até mesmo em obras de pequeno porte. Para trabalhos futuros, sugere-se o uso de outras ferramentas BIM para o mesmo objetivo, o estudo de diretrizes que norteiem a modelagem BIM e os processos, quando o proposito for o planejamento de obras.

\section{Referências}

[1] C. Eastman, P. Teicholz, R. Sacks, and K. Liston, Manual de BIM : Um guia de Modelagem da Informação da Construção para arquitetos, engenheiros, gerentes, construtores $e$ incorporadores. Porto Alegre: Bookman, 2014. Tradução de: Cervantes G. Ayres Filho. 
[2] Succar, Bilal. Building Information Modelling (BIM). 2015. Disponível em: <https://bimdictionary.com/en/building-information-modelling/l/>. Acesso em: 14 nov. 2018.

[3] Andrade, M. L. and Ruschel R. C., "Building Information Modeling (BIM)", In: Kowaltowski, D. C. C. K. et al. (Org.). O processo de projeto em arquitetura: da teoria à tecnologia. São Paulo: "Oficina de textos", 2011.

[4] L. A. Corrêa and F. F. Marchiori, "4D BIM na construção civil e sua relação com lean construction: revisão sistemática da literatura," in $1^{\circ}$ Simpósio Brasileiro de Tecnologia da Informação e Comunicação na Construção (2017), Fortaleza, Ceará, Brazil, 2014, pp. 100107. isbn: 978-85-67169-10-1.

[5] Viana, L. D., Arantes, E. M. "A utilização da ferramenta BIM 5D para obras públicas no Brasil”. In: Encontro nacional de tecnologia do ambiente construído, 17., 2018, Foz do Iguaçu. Anais...Porto Alegre: ANTAC, 2018

[6] Chagas, G. F. C. "Análise comparativa entre fluxos de modelagem para orçamentação em BIM a partir da aplicação em uma residência multifamiliar situada no município de Natal/RN". Trabalho de conclusão de curso (Bacharelado em Engenharia Civil) Universidade Federal do Rio Grande do Norte, Centro de Tecnologia, Curso de Engenharia Civil, Natal, RN, 2019.

[7] Gista, J.P.; Lira, E; Costa, T.; Silva, J. "O uso da tecnologia BIM na quantificação e no planejamento: estudo de caso de residência RN" - brasil. In: Congresso português de building information modelling do instituto superior técnico, Universidade de Lisboa, 4.,2018, Lisboa. Anais eletrônicos...Lisboa: Universidade de Lisboa,2018. 487-495. Doi: 10.5281/zenodo.1226766.

Disponível em: http://www.ptbim.org/img/LivroAtas_ptBIM2018.pdf>. Acesso em: 2 mai. 2020.

[8] S. F. Pereira, "Levantamento de quantitativo a partir de uma Ferramenta BIM," Trabalho de conclusão de Curso (Graduação), Natal, Centro Universitário do Rio Grande do Norte, Rio grande do Norte, Brazil, 2018. 